\title{
Detección de anticuerpos contra Neospora caninum en caninos del área urbana y rural de Cumaral, Meta-Colombia
}

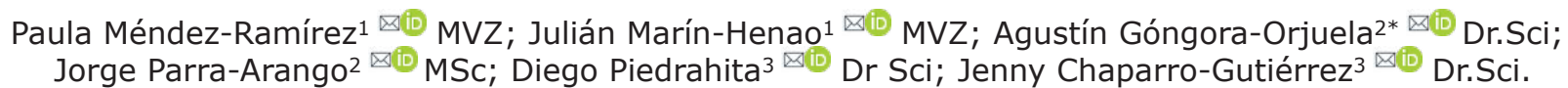

\footnotetext{
${ }^{1}$ Universidad de los Llanos, Escuela de Ciencias Animales, Villavicencio, Meta, Colombia.

¿Universidad de los Llanos. Grupo de Investigación en Reproducción y Genética Animal, Villavicencio, Meta, Colombia.

${ }^{3}$ Universidad de Antioquia, Facultad de Ciencias Agrarias. Grupo de Investigación CIBAV, Medellín, Colombia.

*Correspondencia: agongora@unillanos.edu.co
}

Recibido: Diciembre 2019; Aceptado: Mayo 2020; Publicado: Agosto 2020.

\section{RESUMEN}

Objetivo. Estimar la seroprevalencia a Neospora caninum en caninos del área urbana y rural de Cumaral, Meta y determinar algunos factores de riesgo asociados a la seropositividad. Materiales y métodos. Se efectuó un estudio transversal en 222 perros (112 perros del área urbana y 110 del área rural). El tamaño de la muestra fue calculado en el programa Epidat v. 3.1. Los sueros sanguíneos fueron analizados mediante la técnica de Inmunofluorescencia Indirecta para IgG con un kit comercial. Los análisis de frecuencias, chi-cuadrado, fueron realizados mediante el paquete estadístico SPSS v. 25.0 Resultados. La seroprevalencia general fue 36.9\% (IC95\%: 30.9-43.5 \%). La seropositividad entre los grupos fue: urbana $(38.4 \%)$ y rural $(35.5 \%)(p>0.05)$, machos $(36.9 \%)$ y hembras $(36.9 \%)$ ( $p>0.05)$; en cachorros $(32.7 \%)$, jóvenes $(40.0 \%)$ y adultos $(37.4 \%)(p>0.05)$, en contacto con predios pecuarios $(40.7 \%)$ y sin contacto $(35.2 \%)(p>0.05)$. Conclusiones. La seroprevalencia observada fue alta en las dos poblaciones analizadas y sugiere que los caninos han estado en contacto con el parásito, posiblemente por diferentes fuentes de infección que requieren ser estudiadas posteriormente.

Palabras clave: Epidemiología; Técnica del anticuerpo fluorescente indirecta; ooquistes; aborto (Fuente: DeCs).

\section{ABSTRACT}

Objective. To estimate the seroprevalence to Neospora caninum in canines of the urban and rural area of Cumaral, Meta and determine some risk factors associated with seropositivity. Materials and methods. A cross-sectional study was carried out in 222 dogs (112 dogs from the urban area and 110 dogs from the rural area), the sample size was calculated by using Epidat v program. 3.1. The sera were analyzed using the Indirect Immunofluorescence technique for IgG with a commercial kit. Frequency analyzes by chi-square of independence were performed in SPSS v. 25.0 Results. The general seroprevalence was $36.9 \%$ (95\% CI: 30.9-43.5\%). The seropositivity between the groups

Como citar (Vancouver).

Méndez-Ramírez PS, Marín-Henao JA, Góngora-Orjuela A, Parra-Arango JL, Piedrahita D, Chaparro-Gutiérrez JJ. Detección de anticuerpos contra Neospora caninum en caninos del área urbana y rural de Cumaral, Meta-Colombia. Rev MVZ Córdoba. 2020; 25(3):e1879. https://doi.org/10.21897/rmvz.1879

CEl (los) autor (es), Revista MVZ Córdoba 2020. Este artículo se distribuye bajo los términos de la licencia internacional Creative Commons Attribution c. $\$ 4.0$ (https://creativecommons.org/licenses/by-nc-sa/4.0/), que permite a otros distribuir, remezclar, retocar, y crear a partir de su obra de modo no BY NC SA comercial, siempre y cuando den crédito y licencien sus nuevas creaciones bajo las mismas condiciones. 
was: urban (38.4\%) and rural (35.5\%) ( $p>0.05)$, males $(36.9 \%)$ and females $(36.9 \%)(p>0.05)$; in puppies $(32.7 \%)$, youth $(40.0 \%)$ and adults $(37.4 \%)(p>0.05)$, in contact with livestock farms $(40.7 \%)$ and without contact $(35.2 \%)(p>0.05)$, Conclusions. The seroprevalence observed was high in the two populations analyzed and suggests that the canines have been in contact with the parasite, possibly due to different sources of infection that need to be studied later.

Keywords: Epidemiology; fluorescent antibody technique; indirect; oocysts; abortion (Source:DeCs).

\section{INTRODUCCIÓN}

Neospora caninum es un protozoario intracelular obligado, con características filogenéticas similares a Toxoplasma gondii, su ciclo de vida se caracteriza por la capacidad del parásito de formar quistes en el huésped y ocasionar enfermedad neuromuscular en los perros, sin embargo, los mayores efectos ocurren sobre la reproducción bovina, especialmente abortos y mortalidad neonatal, que ocasionan pérdidas económicas a la producción ganadera mundial (1). Estudios experimentales, confirman que una vez el parásito alcanza el huésped, se mantiene en los perros domésticos y el ganado (2). Los caninos, los coyotes, el oso gris pueden actuar como huéspedes definitivos del protozoario, mientras algunas aves y otros mamíferos lo hacen como huéspedes intermediarios (3).

Dentro de la epidemiología de $N$. caninum, los perros son huéspedes definitivos del parásito, eliminando ooquistes (4) que luego de esporular en el medio ambiente, se constituyen en la forma infectiva para el ganado y otros huéspedes intermediarios (5). El parásito puede ser trasmitido de forma horizontal o vertical, por varias generaciones, lo que hace que la enfermedad se perpetúe a través del tiempo (6). Otra forma de trasmisión es a través de la leche contaminada con taquizoitos (1). Los perros afectados por $N$. caninum, especialmente en infecciones in útero, desarrollan desórdenes neuromusculares severos, con parálisis ascendente y sobre extensión de los miembros posteriores (7).

Respecto a la prevalencia general de Neospora caninum en bovinos, se reportan valores en Norte y Centro América de 24\%, Suramérica 18\%, Asia $15 \%$, Europa 13\%, África y Oceanía $8 \%$ (8), valores que son significativamente menores a los reportados en algunos lugares de Colombia (63$74 \%)(9,10)$. A diferencia del conocimiento que se tiene sobre Neospora en bovinos en Colombia, en los caninos es escasa la información que permita reconocer la importancia del perro en la trasmisión del parásito a los bovinos, situación que se agrava por la inexistencia de vacunas comerciales efectivas para proteger a los animales susceptibles y evitar la posterior infección (11).

El escaso conocimiento de estudios en caninos, pone en evidencia la necesidad de estimar la prevalencia de anticuerpos en regiones con reconocida actividad lechera, en donde los problemas reproductivos que ocasiona $N$. caninum podrían tener mayor impacto y por ende se desconocen, tal es el caso de Cumaral, Meta. En este municipio, se tiene cuantificada una población canina rural y urbana de 3.788 animales (12),

El objetivo de este estudio fue estimar la seroprevalencia de $N$. caninum en perros de las áreas urbana y rural de Cumaral, Meta y determinar algunos factores asociados a la seropositividad. Esta información permitirá coadyuvar en el diseño de programas de control.

\section{MATERIALES Y MÉTODOS}

Ubicación y muestreo. Se hizo un estudio epidemiológico transversal en caninos del Municipio de Cumaral, situado en el Piedemonte llanero, del departamento del Meta, Colombia; Latitud $4016^{\prime} 10^{\prime \prime} \mathrm{N}$ y Longitud 730 29' $11^{\prime \prime} \mathrm{W}$, altitud media de 452 msnm, precipitación de $3000 \mathrm{~mm} / a$ ño y temperatura media anual de $21^{\circ} \mathrm{C}$ (Figura 1). El municipio se encuentra rodeado por bosques tropicales, pasturas para el ganado, cultivos y bosques nativos (13).

El tamaño de muestra se determinó con Epidat 3.1 (14) con la siguiente fórmula:

$n=\frac{N * Z^{2} * p * q}{E E^{2} *(N-1)+Z^{2} * p * q}$

Donde N: población estimada perros de Cumaral 3850 
p: prevalencia hipotética a Neospora caninum

0.19

$q: 1-p ; 1-0.19=0.81$

Z: Confianza 95\%: 1.96

EE: precisión: 0.05

$\mathrm{n}$ : 222 unidades de muestreo

Se efectuó un muestreo aleatorio estratificado por ubicación, rural y urbana, en nueve sitios del área urbana y cinco veredas del área rural.

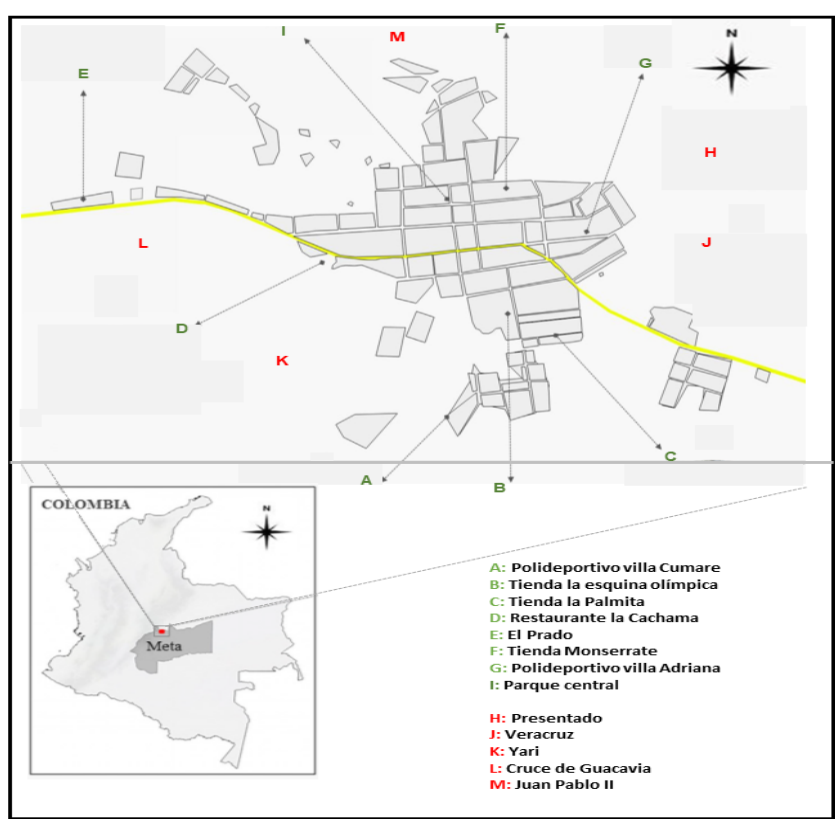

Figura 1. Ubicación y mapa del municipio de Cumaral, Meta. Las letras en color verde corresponde a los sitios de muestreo del área urbana, y en rojo al área rural.

Muestras e información. De cada animal se obtuvieron $5 \mathrm{~mL}$ de sangre por punción de la vena radial con aguja de $21 \mathrm{G} \times 11 / 2$ pulgadas, empleando tubos vacutainer ${ }^{\circledR}$ (Becton Dickinson, USA) al vacío sin anticoagulante. Las muestras fueron transportadas en cadena de frío hasta el laboratorio de Reproducción y Genética Animal de la Universidad de Los Llanos y centrifugadas a $5000 \mathrm{~g}$ por 10 minutos. El suero fue extraído con pipetas estériles, fraccionado en alícuotas de $1 \mathrm{~mL}$ y conservado a $-70^{\circ} \mathrm{C}$ hasta su análisis. Simultáneamente a la toma de las muestras, se diligenció el consentimiento informado y una encuesta epidemiológica mediante entrevista, sobre el sexo, edad, raza, talla, alimentación, ubicación y estado reproductivo de cada animal. Los grupos etarios se determinaron así: cachorros < 12 meses de edad, jóvenes 12 -24 meses, adultos $>24$ meses.
Inmunofluorescencia indirecta para anticuerpos (IFAT). Se utilizó la prueba de IFAT para la detección semicuantitativa de anticuerpos contra la inmunoglobulina G (Laboratorios Fuller, Fullerton, California, USA), siguiendo las instrucciones del fabricante. Brevemente, se realizaron diluciones de los sueros en solución buffer fosfato (PBS) en dilución única 1:16, cada pozo fue marcado con el número serial de la muestra y colocados $10 \mu \mathrm{L}$ de suero y de los controles positivo y negativo. Las láminas se llevaron a incubación por 30 minutos en cámara húmeda a $37^{\circ} \mathrm{C}$, luego de lo cual, fueron lavadas 3 veces con PBS agitándolas para eliminar el exceso de muestra, sin permitir el secado de las láminas. A cada pozo se adicionó 1 gota (10-15 $\mu \mathrm{L}$ ) del conjugado (anti-IgG canina en conejo) y se llevó a incubación por 30 minutos a $37^{\circ} \mathrm{C}$ en cámara húmeda y cuarto oscuro. Las láminas fueron lavadas nuevamente 3 veces con PBS y se les adicionó 2-3 gotas de medio de montaje (glicerol 50\% pH:7.2 más timerosal 0.0005\%), se realizó montaje con una laminilla cubreobjeto y se inició la lectura en cuarto oscuro bajo microscopio a 400X (Olympus IX81, USA). Las muestras con reacción positiva, en la dilución única $1: 16$, fueron consideradas positivas.

Análisis estadístico. Se calculó la seroprevalencia para los factores fijos sexo, estado reproductivo, grupo etario, raza y talla y otros factores como: ubicación, alimentación, permanencia y trastornos reproductivos en bovinos con perros ubicados en predios con ganadería. Los intervalos de confianza de las proporciones se establecieron por el método de Wilson (15). Se realizó análisis de frecuencias por prueba de independencia, chi-cuadrado $\left(X^{2}\right)$ para establecer asociación o independencia entre los factores epidemiológicos y la respuesta serológica a Neospora caninum. La edad no presentó distribución normal (Kolmogorov, $\mathrm{p}<0.01$ ) siendo evaluada la diferencia entre grupos, con prueba de Kruskall-Wallis (KW). El software empleado fue Epidat 3.1 (13) e IBM SPSS-25.

Aspectos éticos. Este estudio fue aprobado por el comité de Bioética de la Universidad de los Llanos con acta No 13 del 6 de diciembre de 2017.

\section{RESULTADOS}

La seroprevalencia general de anticuerpos IgG contra $N$. caninum fue $36.9 \%(82 / 222)$ (IC $95 \% 30.9-43.5)$. Las figuras $2 \mathrm{~A}$ y $2 \mathrm{~B}$ presentan una prueba positiva y negativa a IFAT para la presencia de anticuerpos IgG contra Neospora caninum. 

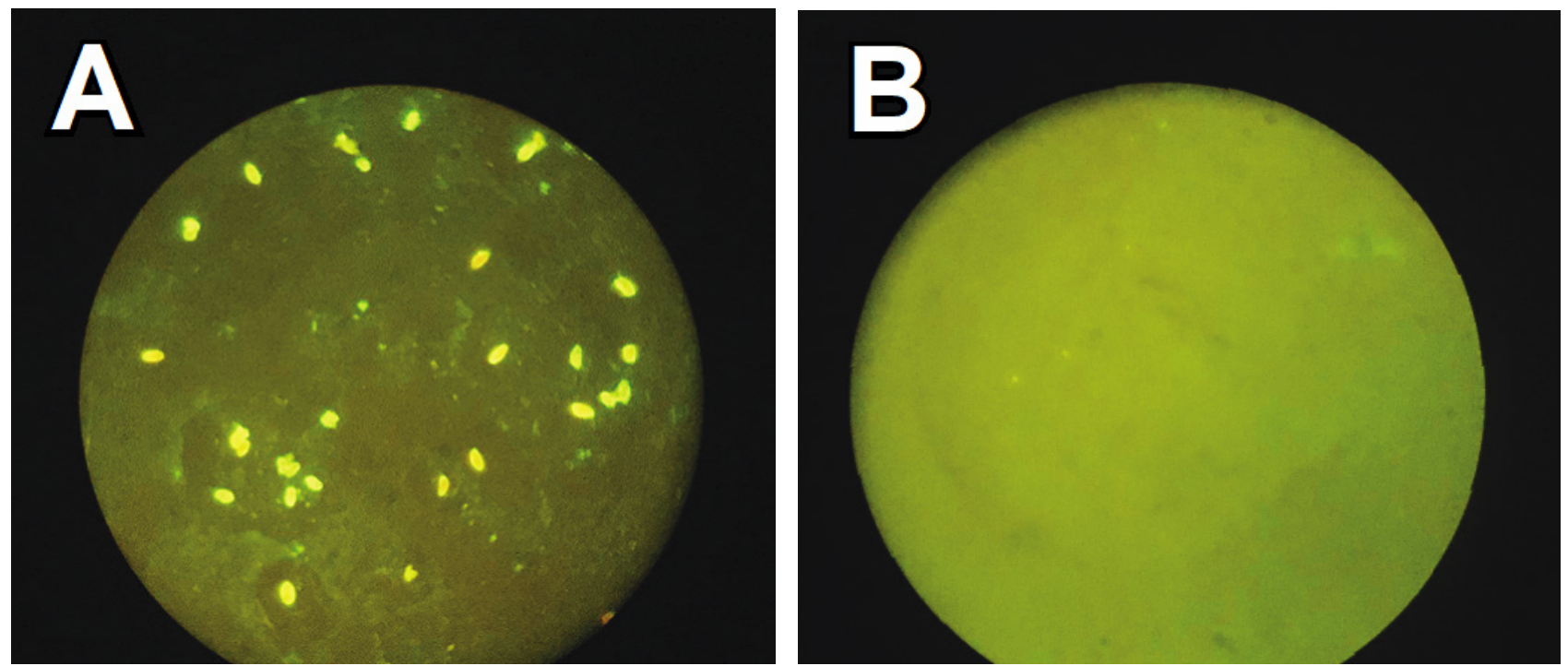

Figura 2. Prueba de IFAT, A. Prueba positiva, obsérvese presencia de taquizoitos fluorescentes de Neospora caninum. B. Control negativo,. Aumento 10X.

No se presentaron diferencias para la edad, entre perros seropositivos y seronegativos (KW $X^{2}$ : 1.501 ; gl: 1 ; Significancia 0.221 ) siendo de 36 meses en ambos grupos. La seroprevalencia en cachorros, jóvenes y adultos fue: 32.7, 40.0 y $37.4 \%$ respectivamente sin diferencias significativas entre grupos (Tabla 1 ).

Los factores fijos: sexo, grupo etario, raza, talla y estado reproductivo, no se encontraron asociados a la seropositividad a N. caninum (Tabla 1 ).

Las proporciones de seropositivos en la zona urbana $38.4 \%$ y la zona rural $35.4 \%$, no presentaron diferencias significativas entre si, igual resultado se observó para el tipo de alimentación y la permanencia de los animales en la calle o en la casa (Tabla 2 ).

El contacto de los perros con predios pecuarios, con bovinos como especie doméstica dominante, fue independiente del estatus serológico a $N$. caninum. La disposición correcta o inadecuada de placentas bovinas fue independiente del estatus serológico a $N$. caninum de los perros, no se presentó asociación de aborto bovino con perros seropositivos a $N$. caninum (Tabla 3 ).

Tabla 1. Factores fijos asociados con la seropositividad a Neospora caninum en perros de Cumaral, Meta.

\begin{tabular}{|c|c|c|c|c|c|c|}
\hline Factor & Condición & $\begin{array}{c}\text { Seropositivos } \\
\text { N. caninum }\end{array}$ & $\begin{array}{c}\text { Porcentaje de } \\
\text { seropositivos }\end{array}$ & $\begin{array}{c}\text { IC } 95 \% \\
\text { Seropositivos } \\
\end{array}$ & $\mathrm{x}^{2} \mathrm{gl}$ & Sig. \\
\hline \multirow[t]{2}{*}{ Sexo } & Machos & $41 / 111$ & 36.9 & $28.5-46.2$ & 0.000 & \multirow{2}{*}{1.000} \\
\hline & Hembras & $41 / 111$ & 36.9 & $28.5-46.2$ & 1 & \\
\hline \multirow[t]{3}{*}{ Grupo etario } & Cachorros & $16 / 49$ & 32.7 & $21.2-46.6$ & 0.599 & \multirow{3}{*}{0.741} \\
\hline & Jóvenes & $20 / 50$ & 40.0 & $27.6-53.8$ & 2 & \\
\hline & Adultos & $46 / 123$ & 37.4 & $29.4-46.2$ & & \\
\hline \multirow[t]{2}{*}{ Estado reproductivo } & Castrado & $16 / 36$ & 44.0 & $29.5-60.4$ & 0.998 & \multirow{2}{*}{0.318} \\
\hline & Entero & $18 / 53$ & 34.0 & $22.7-47.4$ & 1 & \\
\hline \multirow[t]{2}{*}{ Raza } & Cruzado & $55 / 154$ & 35.7 & $20.6-43.6$ & 0.323 & \multirow{2}{*}{0.570} \\
\hline & De Raza & $27 / 68$ & 39.7 & $28.9-51.6$ & 1 & \\
\hline \multirow[t]{3}{*}{ Talla } & Pequeña & $10 / 38$ & 26.3 & $15.0-42.0$ & 3.865 & \multirow[t]{3}{*}{0.145} \\
\hline & Mediana & $58 / 139$ & 41.7 & $33.9-50.0$ & 2 & \\
\hline & Grande & $14 / 45$ & 31.1 & $19.5-49.7$ & & \\
\hline
\end{tabular}

IC: Intervalo de confianza; $x^{2}$ : Chi-cuadrado; gl: grados de libertad, Sig: Significancia 
Tabla 2. Otros factores asociados a la seropositividad a Neospora caninum en perros de Cumaral, Meta y factores asociados.

\begin{tabular}{lcccccc}
\hline \multicolumn{1}{c}{ Factor } & Condición & $\begin{array}{c}\text { Seropositivos } \\
\text { N. caninum }\end{array}$ & $\begin{array}{c}\text { Porcentaje } \\
\text { seropositivos }\end{array}$ & $\begin{array}{c}\text { IC 95\% } \\
\text { Seropositivos }\end{array}$ & $\mathbf{X}^{\mathbf{2}} \mathbf{~ g l}$ & Sig. \\
\hline Ubicación & Rural & $39 / 110$ & 35.5 & $27.1-44.8$ & 0.206 & 0.650 \\
& Urbano & $43 / 112$ & 38.4 & $29.9-47.6$ & 1 & 0.890 \\
Alimentación & Casera & $2 / 6$ & 33.3 & $9.68-70.0$ & 0.232 & 2 \\
& Concentrado & $14 / 34$ & 41.2 & $26.4-57.8$ & 2 & \\
& Mixta & $18 / 49$ & 36.7 & $24.7-50.7$ & & 0.477 \\
Permanencia & Calle & $9 / 20$ & 45.0 & $25.8-69.8$ & 0.505 & 1 \\
& Casa & $25 / 69$ & 36.2 & $25.9-48.0$ & 1 & \\
\hline
\end{tabular}

IC: Intervalo de confianza; $X^{2}$ : Chi-cuadrado; gl: grados de libertad, Sig: Significancia

Tabla 3. Factores relacionados con contacto con bovinos, asociados a la seropositividad a Neospora caninum en perros de Cumaral.

\begin{tabular}{|c|c|c|c|c|c|c|}
\hline Factor & Condición & $\begin{array}{c}\text { Seropositivos } \\
\text { N. caninum }\end{array}$ & $\begin{array}{l}\text { Porcentaje de } \\
\text { seropositivos }\end{array}$ & $\begin{array}{c}\text { IC } 95 \% \\
\text { Seropositivos }\end{array}$ & $x^{2} \mathrm{gl}$ & Sig \\
\hline \multirow{2}{*}{$\begin{array}{l}\text { Contacto predios } \\
\text { pecuarios }\end{array}$} & $\mathrm{Si}$ & $12 / 35$ & 34.3 & $20.8-50.6$ & 0.475 & 0.540 \\
\hline & No & $22 / 54$ & 40.7 & $28.7-54.0$ & 1 & \\
\hline \multirow{2}{*}{$\begin{array}{l}\text { Disposición } \\
\text { placentas bovinas }\end{array}$} & Adecuada & $6 / 14$ & 42.9 & $21.4-67.4$ & 0.295 & 0.587 \\
\hline & Inadecuada & $25 / 71$ & 35.2 & $25.1-46.8$ & 1 & \\
\hline \multirow[t]{2}{*}{ Aborto Bovino } & $\mathrm{Si}$ & $1 / 5$ & 20.0 & $3.60-62.5$ & Prueba Fisher & 0.648 \\
\hline & No & $30 / 80$ & 37.5 & $27.7-48.5$ & & \\
\hline
\end{tabular}

IC: Intervalo de confianza; $X^{2}$ : Chi-cuadrado; gl: grados de libertad, Sig: Significancia

\section{DISCUSIÓN}

El presente estudio demuestra, la presencia de anticuerpos contra el $N$. caninum en caninos de las áreas urbana y rural del municipio de Cumaral, Meta, lo que sugiere que las poblaciones han estado en contacto con el parásito y pueden representar un riesgo de trasmisión horizontal al ganado, ya que los caninos se consideran los huéspedes definitivos del parásito. Aunque no se observaron diferencias entre las dos poblaciones, diversos estudios señalan una mayor seroprevalencia en caninos de áreas rurales. En perros de Teherán (Irán) la prevalencia fue menor para ambas poblaciones que las encontradas en este estudio (16).

En el Noroeste de Italia mediante IFAT los valores de prevalencia fueron Perros Rurales (PR): $(36.4 \%),(19.5 \%)$ y $(9.9 \%)$ y Perros urbanos (PU): $(20.2 \%),(10.6 \%)$ y $(4.8 \%)$ para las diluciones $1: 40,1: 80$ y $1: 160$ respectivamente, resultados de difícil comparación con el presente trabajo que utilizó una única dilución 1:16. (17). Contrariamente en caninos que provenían de fincas del centro de Italia, la prevalencia fue mayor al 46\% (18). En Brasil los perros del área rural tuvieron más riesgo de infección que aquellos de las áreas urbanas (19).

En Argentina, Basso et al (20) reportaron una mayor prevalencia en perros de fincas lecheras $(48 \%)$ y de ganado de carne $(54.2 \%)$ que en perros de áreas urbanas (22.2\%). En Japón, Sawada et al (21), evaluando perros de fincas lecheras reportaron una prevalencia de 31\% vs $7 \%$ en perros del área urbana. En Holanda, Wouda et al (22) reportaron $23.6 \%$ en perros de fincas versus $5.5 \%$ en perros de áreas urbanas

En otros estudios la prevalencia ha sido menor a la del presente reporte en ambas poblaciones de caninos, como lo observado en la provincia Henan, área central de China PR: (18\%) y PU: $(11.0 \%)$ (23), en Chile en la IX región del país PR: $(26 \%)$, PU: $(12.5 \%)(p<0.05)(24)$ y en el Estado de Yaracuy (Venezuela) PR: (20.6\%) y PU: (5.1\%) $\mathrm{p}<0.05$ ) (25). Independiente del origen de las muestras las prevalencias varían ampliamente entre regiones y países, así en Polonia y Alemania mediante ELISA se reportaron valores de un $21.7 \%$ y $7.3 \%$ de seropositividad a $N$. caninum, respectivamente $(26,27)$ y en Victoria (Australia) en perros domésticos mediante IFAT fué (32.9\%) (28). 
En Colombia, un estudio realizado en el Rosal, Cundinamarca, se examinaron por PCR excretas de 60 perros, residentes en 30 fincas del sistema de lechería especializada, encontrando $21.6 \%$ perros y $33.3 \%$ de los predios con DNA de Neospora caninum (29).

Si bien los anteriores estudios señalan una mayor prevalencia en los perros de fincas o de áreas rurales, que reflejan condiciones epidemiológicas distintas de las áreas urbanas, es posible que en este estudio, el no observar diferencias entre las dos poblaciones estudiadas se explique por diversas condiciones, entre ellas: la alta movilidad de los animales del área rural a la urbana y viceversa, favorecida por una estrecha contiguidad entre las dos zonas; el municipio de Cumaral, se encuentra rodeado de fincas, especialmente productoras de leche, donde los caninos eventualmente pueden deambular libremente, realizando la excreción de materia fecal y pudiendo consumir restos de placentas y fetos abortados. Otra explicación podría estar relacionada con la alimentación de los caninos en la zona urbana, en donde los habitantes tienen un alto consumo de carne y los sobrantes de dicha carne se utilizan para la alimentación de los caninos. Es conocido que la carne cruda o mal cocida puede contener los quistes del parásito y ser una fuente de infección (30).

Otra hipótesis, podría estar relacionada con la trasmisión vertical del parásito, aunque en el estudio no se observaron animales con signos clínicos compatibles con neosporosis. En 50 caninos de consulta externa Veterinaria en la clínica Dover de Bogotá, y que presentaron al menos un signo neurológico, $12 \%$ animales fueron seropositivos a Neospora caninum por IFAT y ninguno presentó ooquistes en materia fecal (31). De igual forma en Inglaterra en un estudio en 373 hembras caninas el $13 \%$ presentaron títulos mayores de 1:50 por IFAT, el $50 \%$ de las crías nacieron seropositivas y posteriormente $25 \%$ de ellas desarrollaron enfermedad clínica compatible con neosporosis; tres perras produjeron en posteriores preñeces cachorros infectados (32).

Aunque no fueron estudiadas las crías de los animales seropositivos, la ausencia de formas clínicas de la neosporosis en los perros seropositivos puede estar relacionada con cepas de baja patogenicidad circulantes en el municipio de Cumaral, no obstante, son escasos los estudios a este respecto (6). De otro lado, existen pocos modelos animales disponibles para probar la variación en la patogenicidad, en un estudio bajo el modelo ratón algunas cepas de Neospora caninum fueron más patógenas (33).

De igual forma, deben considerarse otras posibles fuentes de infección principalmente a través del contacto con especies silvestres, dado que el municipio y la región poseen una alta biodiversidad (34). Previamente, se ha descrito la presencia de seropositividad a Neospora en carnivoros silvestres y otras especies silvestres incluyendo el dingo, coyotes, zorros colorados $y$ aves (35).

Respecto a la prueba de IFAT utilizada en el estudio, es considerada de elección para el diagnóstico de Neospora caninum (36). Campero et al (37), analizando diversas pruebas serológicas encontraron una alta sensibilidad y especificidad ( $>95 \%$ ) y concordancia entre IFAT, Inmunobloting y ELISA-p38. En otra investigación la prevalencia de anticuerpos medidos por ELISA competitiva e IFAT no varió significativamente entre pruebas $32.9 \%$ y $29.8 \%$, respectivamente (26). Si bien es posible la presencia de reacciones cruzadas entre Neospora caninum con otros parásitos protozoarios como Toxoplasma gondii, en el caso de IFAT se consideran mínimas (38).

Con respecto a la seropositividad de acuerdo con la edad, la mayor positividad fue observada en los animales jóvenes (40\%) que coincide con los datos reportados, en perros de Victoria, Australia, sin embargo en el grupo de adultos se encontró la mayor prevalencia (28). La raza, sexo y edad, no fueron factores asociados a la seroprevalencia, como se observó en caninos del área central de China (23). Por el contrario en Polonia, la prevalencia fue mayor en las hembras que los machos $(28.0 \%$ y $17.3 \%$ respectivamente $p<0.05)$. Resultados similares al presente estudio, para las variables edad, sexo, raza y hábitos alimenticios (18).

Los resultados de este estudio, tienen un importante significado epidemiológico, puesto que cualquiera de los dos grupos de caninos representan un riesgo para el ganado bovino. Wouda et al (22), han observado en las fincas en donde los perros conviven con el ganado, un aumento en el riesgo de infección con Neospora, lo cual sugiere una vigilancia permanente frente a la infección y la enfermedad, y la necesidad de una educación continua a los profesionales, mayordomos, propietarios de ganado y de las mascotas. 
Se concluye que la seroprevalencia es alta sin diferencias entre los perros del área urbana y rural que sugiere que han estado en contacto con el parásito, posiblemente por diferentes fuentes de infección que requieren ser estudiadas como las posibles implicaciones de trasmisión horizontal para el ganado.

\section{Conflicto de Intereses}

Los autores declaran no tener conflicto de intereses.

\section{Agradecimientos}

Dirección general de investigaciones de la Universidad de los Llanos, por el apoyo financiero a este proyecto (código:CO4-F01-004-2017) funcionarios de la secretaría departamental de salud del Meta y propietarios de los animales participantes de la investigación.

\section{REFERENCIAS}

1. Dubey JP, Schares G, Ortega-Mora LM. Epidemiology and control of neosporosis and Neospora caninum. Clinic Microbiol Rev. 2007; 20(2):323-367. https://doi. org/10.1128/CMR.00031-06

2. Regidor-Cerrillo J, Díez-Fuertes F, GarcíaCulebras A, Moore DP, González-Warleta $M$, Cuevas C, et al. Genetic diversity and geographic population structure of bovine Neospora caninum by microsatellite genotyping analysis. PLoS ONE. 2013; 8(8):e72678. https://doi.org/10.1371/ journal.pone. 0072678

3. Prandini da Costa Reis R, Crisman R, Roser M, Malik R, Slapeta J. Neonatal neosporosis in a 2-week-old Bernese mountain dog infected with multiple Neospora caninum strains based on MS10 microsatellite analysis. Vet Parasitol. 2016; 15(221):134-138. https:// doi.org/10.1016/j.vetpar.2016.03.023

4. Nazir MM, Maqbool A, Akhtar M, Ayaz M, Ahmad AN, Ashraf K, et al. Neospora caninum prevalence in dogs raised under different living conditions. Vet Parasitol. 2014; 204(3-4):364-368. https://doi. org/10.1016/j.vetpar.2014.05.041

5. Arunvipas $P$, Inpankaew $T$, Jittapalapong S. Risk factors of Neospora caninum infection in dogs and cats in dairy farms in Western Thailand. Trop Anim Health Prod. 2012; 44(5): 1117-1121. https://doi. org/10.1007/s11250-011-0048-2
6. Dubey JP, Schares G, Ortega-Mora LM. Epidemiology and Control of Neosporosis and Neospora caninum. Clinic Microbiol Rev. 2007; 20(2):323-367. https://doi. org/10.1128/CMR.00031-06

7. Langoni H, Matteucci G, Medici B, Camossi LG, Richini- Pereira VB, Silva RC. Detection and molecular analysis of Toxoplasma gondii and Neospora caninum from dogs with neurological disorders. Rev Soc Bras Med Trop. 2012; 45(3):365-368. http://dx.doi. org/10.1590/S0037-86822012000300016

8. Ribeiro CM, Soares IR, Mendes RG, de Santis Bastos PA, Katagiri S, Renato Zavilenski RB. Meta-analysis of the prevalence and risk factors associated with bovine neosporosis. Tropical Animal Health and Production. 2019; 51(7):1783-1800 https://doi.org/10.1007/ s11250-019-01929-8

9. Cardona JA, Martínez Y, Betancur CA. Seroepidemiología de hembras bovinas naturalmente infectadas por Neospora caninum en Córdoba, Colombia. Rev UDCA Act \& Div Cient. 2015; 18(2):401-408 https://revistas.udca.edu.co/index.php/ ruadc/article/view/166/1281

10. Vargas-Niño A, Vargas J, Parra J, Vásquez M, Góngora A, Mogollón-Waltero EM. Estado serológico a IBR, DVB, Leucosis, Leptospira y Neospora caninum en hembras bovinas del Departamento de Santander, Colombia. Rev MVZ Córdoba. 2018; 23(2):6671-6680. https://doi.org/10.21897/rmvz.1341 
11. Silva R, Machado G. Canine neosporosis: perspectives on pathogenesis and management. Vet Med. 2016; 26(7):59-70. https://doi.org/10.2147/VMRR.S76969

12. Ministerio de Salud. Reporte de vacunación antirrábica de perros y gatos, Colombia 2017. En http://www.minsalud.gov.co/sites/ rid/Lists/BibliotecaDigital/RIDE/VS/PP/SA/ nacional-municipio-2017.pdf. Revisado $\underline{5 / 02 / 2020}$

13. IDEAM, 2014. Atlas climatológico de Colombia. Instituto de Hidrología, Meteorología y Estudios Ambientales (IDEAM), Bogotá, Colombia. http:// documentacion.ideam.gov.co/cgi-bin/koha/ opac-detail.pl?biblionumber $=1381 \&$ shelfbro wse itemnumber $=1465$

14. EPIDAT 3.1. 2006. Programa para análisis de datos epidemiológicos tabulados. Versión 3.1. Xunta de Galicia, Conselleria de sanidade-Organización Panamericana de la salud. OPS. https://www.sergas.es/Saudepublica/Epidat-3-1-descargar-Epidat-3-1(espanol)

15. Newcombe RG, Merino C. Intervalos de confianza para las estimaciones de proporciones y las diferencias entre ellas. Interdisciplinaria. 2006; 23 (2):141-154.

16. Haddadzadeh HR, Sadrebazzaz A. Malmasi A, Ardakani HT, Nia PK, Sadreshirazi N. Seroprevalence of Neospora caninum infection in dogs from rural and urban environments in Tehran, Iran. Parasitol Res. 2007; 101 (6):1563-1565. https:// doi.org/10.1007/s00436-007-0678-5

17. Ferroglio $E$, Pasino $M$, Ronco $F$, Bena $A$, Trisciuoglio. A Seroprevalence of Antibodies to Neospora caninum in Urban and Rural Dogs in north-west Italy. Zoonoses Public Health. 2007; 54:135-139. https://doi. org/10.1111/j.1863-2378.2007.01033.x

18. Robbe D, Passarelli A, Gloria A, Di Cesare A, Capelli G, Iorio R, Traversa D. Neospora caninum seropositivity and reproductive risk factors in dogs. Exp Parasitol. 2016; 164:31-35. https://doi.org/10.1016/j. exppara.2016.02.003
19. Nogueira CI, Mesquita LP, Abreu CC, Nakagaki KY, Seixas JN, Bezerra PS, et al. Risk factors associated with seroprevalence of Neospora caninum in dogs from urban and rural areas of milk and coffee production in Minas Gerais State, Brazil. Epidemiol Infect. 2013; 141(11):2286-2293. https://doi. org/10.1017/S0950268813000162

20. Basso $W$, Venturini $L$, Venturini $M$, Moore $P$, Rambeau M, Unzaga J, et al. Prevalence of Neospora caninum infection in dogs from beef cattle farms, dairy farms, and from urban areas of Argentina. J Parasitol. 2001; 87(4):906907. https://doi.org/10.1645/00223395(2001)087[0906:PONCII]2.0.CO;2

21. Sawada M, Park $\mathrm{CH}$, Kondo H, Morita T, Shimada A, Yamane I, et al. Serological survey of antibody to Neospora caninum in Japanese dogs. J Vet Med Sci. 1998; 60(7):853-854. https://doi.org/10.1292/ jvms.60.853

22. Wouda W, Dijkstra T, Kramer AM, van Maanen C, Brinkhof JM. Seroepidemiological evidence for a relationship between Neospora caninum infections in dogs and cattle. Int J Parasitol. 1999; 29(10):1677-1682. https:// doi.org/10.1016/s0020-7519(99)00105-8

23. Wang $S$, Yao Z, Zhang N, Wang D, Ma J, Liu S, Zheng B, Zhang B, Liu K, Zhang H. Serological study of Neospora caninum infection in dogs in central China. Parasite. 2016, 23(25):1-5. https://doi.org/10.1051/ parasite/2016025

24. Patitucci AN, Phil M, Pérez MJ, Rozas MA, Israel KF. Neosporosis canine: detection of sera antibodies in rural and urban canine population of Chile. Arch Med Vet. 2001; 33 (2):227-232. http://dx.doi.org/10.4067/ $\underline{\mathrm{S} 0301-732 \times 2001000200011}$

25. Escalona JJ, Corro AC, Suárez CE, Castillo TA, Pineda YA. Seropositividad a Neospora caninum en perros de áreas rurales y urbanas del estado Yaracuy, Venezuela. Rev Fac Cs Vets. UCV. 2013; 54(1):29-34. http://saber.ucv.ve/ojs/index.php/revisfcv/ article/view/5146/4953 
26. Gozdzik K, Wrzesien R, Wielgosz-Ostolska A, Bien J, Kozak- Ljunggren M, Cabaj W. Prevalence of antibodies against Neospora caninum in dogs from urban areas in Central Poland. Parasitology Research. 2011; 108(4):991-996. https://doi.org/10.1007/ $\underline{\text { s00436-010-2143-0 }}$

27. Villagra-Blanco $R$, Angelova $L$, Conze $T$, Schares G, Bärwald A, Taubert A, Hermosilla C, Wehrend A. Seroprevalence of Neospora caninum-specific antibodies in German breeding bitches. Parasites \& Vectors. 2018; 11(96):2-6. https://doi.org/10.1186/ s13071-018-2683-1

28. Sloan S, Šlapeta J, Jabbar A, Hunnam J, De Groef B, Rawlin G, McCowan C. High seroprevalance of Neospora caninum in dogs in Victoria, Australia, compared to 20 years ago. Parasites \& Vectors. 2017; 10(1):503. https://doi.org/10.1186/s13071-017-2464-2

29. Bulla-Blanco KD, Vanegas-Rojas PX. (2015). Identificación de neospora caninum en materia fecal de 60 caninos en hatos lecheros en el municipio el Rosal, Cundinamarca. Retrieved from https://ciencia.lasalle.edu. co/medicina veterinaria/104

30. Cedeño D, Benavides B. Seroprevalencia y factores de riesgo asociados a Neospora caninum en ganado lechero en el municipio de Pasto, Colombia. Rev MVZ Córboba. 2013; 18(1):3311-3316. https://doi. org/10.21897/rmvz.193

31. Ravelo-Salcedo L. (2009). Estudio clínico, serológico y coprológico preliminar de Neospora Caninum en caninos de la clínica veterinaria Dover Bogotá - Colombia. Retrieved from https://ciencia.lasalle.edu. $\mathrm{co/medicina} \mathrm{veterinaria/296}$
32. Barber JS, Trees AJ. Naturally ocurring vertical transmission of Neospora caninum in dogs. Int J Parasitol. 1998; 28:57-64. https://doi. org/10.1016/s0020-7519(97)00171-9

33. McInnes LM, Irwin $P$, Palmer DG, Ryan UM. In vitro isolation and characterization of the first canine Neospora caninum isolate in Australia. Vet Parasitol. 2006; 137:355-363. https://doi.org/10.1016/j. vetpar.2006.01.018

34. Rangel O. La biodiversidad de Colombia: significado y distribución regional. Rev Acad Colomb Cienc Ex Fis Nat. 2015; 39(151):176-200. http://dx.doi. org/10.18257/raccefyn.136

35. Donahoe $S L$, Lindsay $S A$, Krockenberger $M$, Phalen D, Šlapeta J. A review of neosporosis and pathologic findings of Neospora caninum infection in wildlife. Int J Parasitol Parasites Wildl. 2015; 4:216-38. http://doi. org/10.1016/j.ijppaw.2015.04.002

36. Atkinson R, Harper PA, Reichel MP, Ellis JT. Progress in the serodiagnosis of Neospora caninum infections of cattle. Parasitol Today. 2000; 16(3):110-114. https://doi. org/10.1016/s0169-4758(99)01604-X

37. Campero LM, Minke L, Moré G, Rambeaud M, Bacigalupe D, Moore DP, et al. Evaluation and comparison of serological methods for the detection of bovine neosporosis in Argentina. Rev Argent Microbiol. 2015; 47(4):295-301. https://doi.org/10.1016/j. ram.2015.07.002

38. Hemphill A, Gottstein B. A European perspective on Neospora caninum. Int J Parasitol. 2000; 30:877-924. https://doi. org/10.1016/S0020-7519(00)000722 